\title{
FINE TUNING THE NEW REFUGEE DETERMINATION PROCESS
}

\author{
Arul S. Aruliah, M.Sc (Eng)
}

The new refugee determination system has been in effect since January 1 , 1989. It took nearly two and half years of Parliament, including an emergency recall in the Summer of '87. Three successive cabinet ministers were involved before this bill was enacted.

The Immigration and Refugee Board (IRB) members, under the chairmanship of former human rights commissioner, Gordon Fairweather, have brought a degree of respect to the body. Immigration Minister Barbara McDougall, to her credit, effectively nullified the controversial 'safe third country clause' by including no country in that list. Otherwise, it would have had a deleterious effect on the well earned international recognition of Canada as a leader in refugee policy. The presence of a credible basis hearing has virtually eliminated manifestly unfounded chaims ever reaching the border, let alone the determination system.

An analysis of data for the year 1989 and the first half of 1990, however, indicates that the new system is in need of some form of fine tuning to be fully effective. There was a total of 24,519 claims before the Board during this period. About 94 percent of the cases were dealt with at the first level credible basis hearing and about 95 percent of those claimants were referred for full hearing. Only 52 percent of total claims, however, have been dealt with 80 far, and some of the cases are now being scheduled for hearing well into 1991. Besides there is progressive build-up Arontlogi) of claimants waiting for a credible basis hearing as well. Though the numbers are a far ory from the years of waiting experienced by the claimants in the past or still waiting in the pre-1989 Backlog, this current build-up is bound to damage the effectiveness of the newly installed system. It has the potential for another backlog of claimants. One alternative is for Ottawa to hire additional personnel to reduce the lineup. But how long would the line-up be two years down the road? Even if it is assumed that money is available (of course it is not), would this be the best course of action?

Let us look at the data again. This is the most independent and least unblased data bank for convention refugee determination in Canada to date and indeed anywhere in the world. The acceptance rates at the credible basis hearing for each of the five leading countries in the system were in the range of 98.0 to 99.8 percent and their corresponding rates at the full hearing were in the range of 88.5 to 97.7 percent in the first year of operation. This subgroup, which constitutes a full twothirds of the full hearing population, had a 99.2 percent scceptance level at the credible hearing stage and 93.5 percent acceptance as conoention refugess at the full hearing. A similar trend is evident in the first half year results for the leading sounce countries

One has immediately to pose the question, therefore, whether the system is employing the most effective mechanien to pick out 65 claimants out of every 1000 chims from this subgroup. Infactevery one of themhavebeen found to have a credible basts for their claims, except that they did not fall neatly into the definition of a convention refugee, and in some of these cases the Minister exercised her discretionary powers, to her credit again, to protect them from removal to their country of alleged persecution. Therefore, it is fair to conclude that if this patently expensive method of second cereening is allowed to continue, this process is unlikely to contribute to the effectiveness of the system.

A desired level of effectiveness in the system can be achieved by developing a set of bias free quantitutive criteria to create a Designated Class or an Administrative Program, based entirely on quasi-judicial IRB data bank information. Members of this group can then be dealt with administratively. A similar system was brought in by then Minister of Immigration (State) Mr. Walter McLean in May 1986, known as B1 list, which was in effect till February 1987. It was, however, largely based on qualitatioe asecsements of the country's human rights recond. There was no mechanism to make any distinction between the persecuted and the persecutor from a given country. Invariably, both groups of claimants do come from the same country, except in instances where foreign occupation forces are involved. This deficiency has now been addresed by the credible basis hearing for eoery one of the claimants shortly after their arrival. The record indicates that a procesoing rate at the first level hearing is very satisfactory indeed.

It is imperative that a set of criterla, which defines any designated class, should have automatic self-renewing capabilities so that no country has a permanent place in that list but equally any country con gain access into that group simply based on a significant IRB sample size and its quantitatioe assessment at yearly or half-yearly intervals.

As an example, if a claimant has been determined to have a credible basis for his claim, then he should be considered to be an eligible member of the proposed dexignated clase if $(a)$ the country of alleged persecution records an scopptance rateof, say, a minimum of so pencent at thecredible basis stage, and (b) a minimum of, say, 300 claims from that country have been determined at the full hearing stage and there was an acceptance rate of, 8 an, 85 percent during that assessment period. The first 


\section{DRAWING CONCLUSIONS}

(IRB Data Period: Jan. 1,1989 - June 30, 1990)

\section{REFUGEE CLAIMS IN 1989 AND FIRST HALF OF 1990}

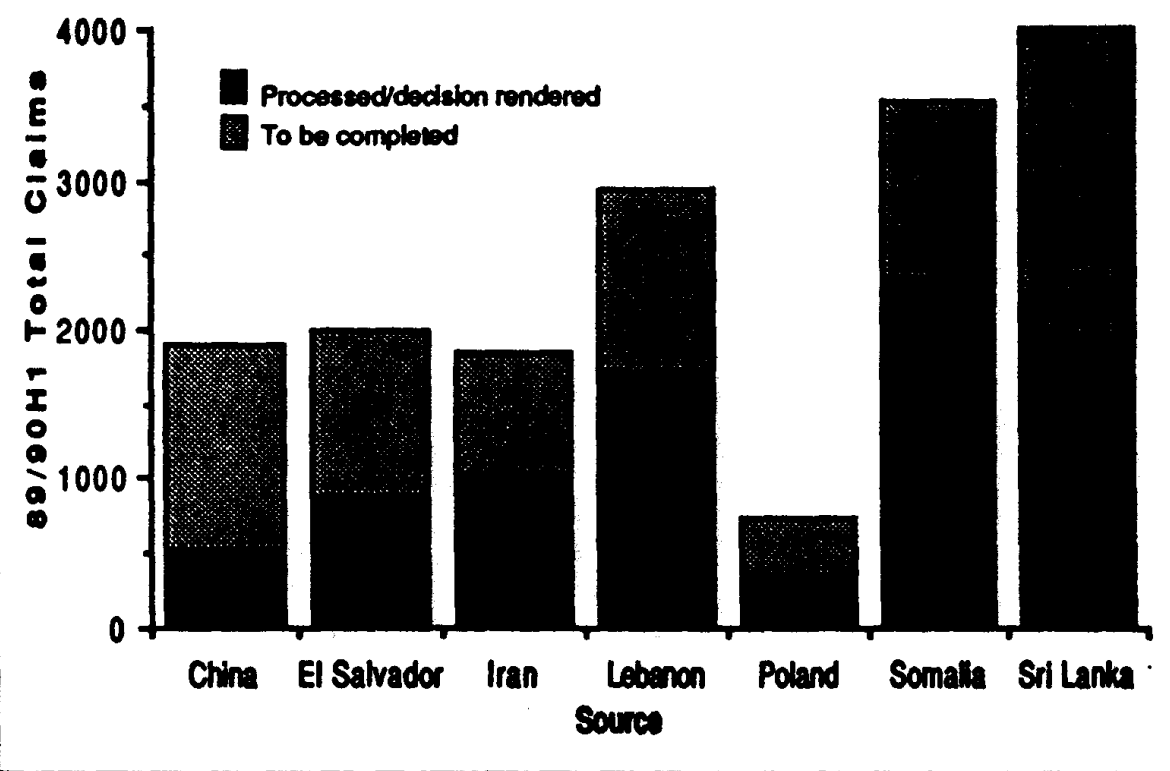

\section{DECISION RENDERED AND ACCEPTANCE LEVEL OF} SEVEN LEADING SOURCE COUNTRIES.

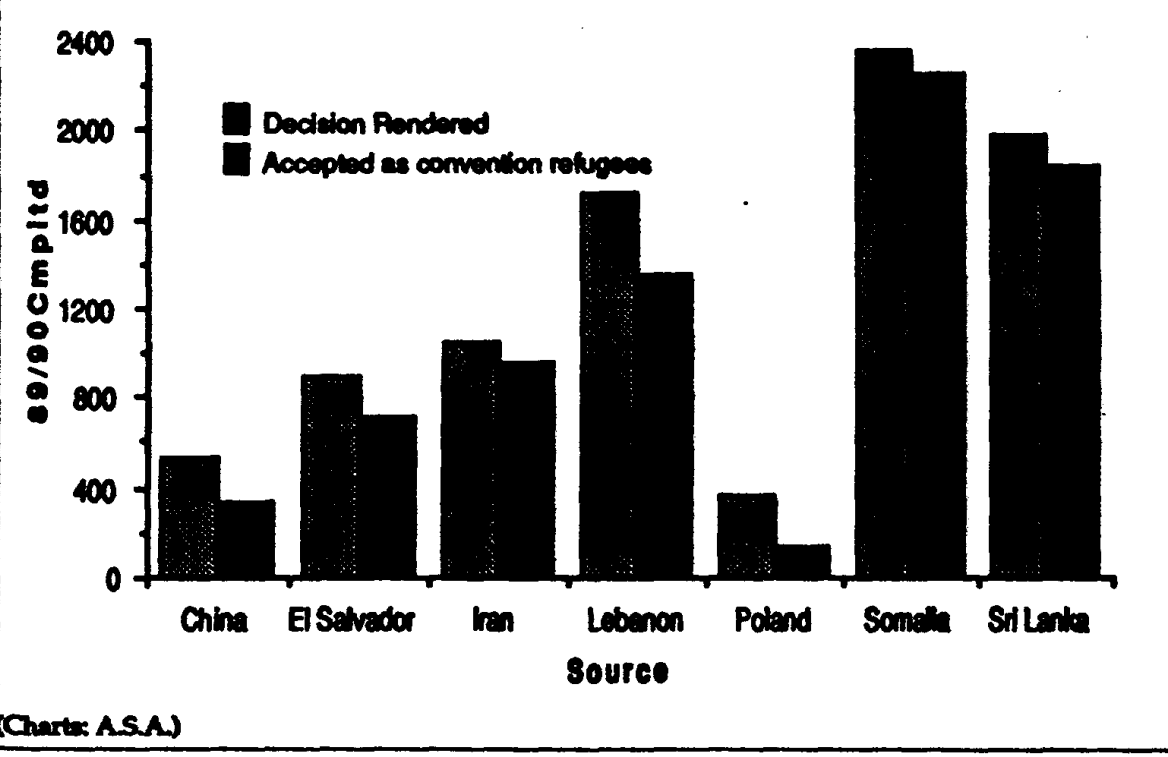

criterion would ensure that when the human rights situation improves in a given country, then it will automatically exit from the designated class list at the next assessment period. The second criterion would facilitate a deserving member to gain access to that group.

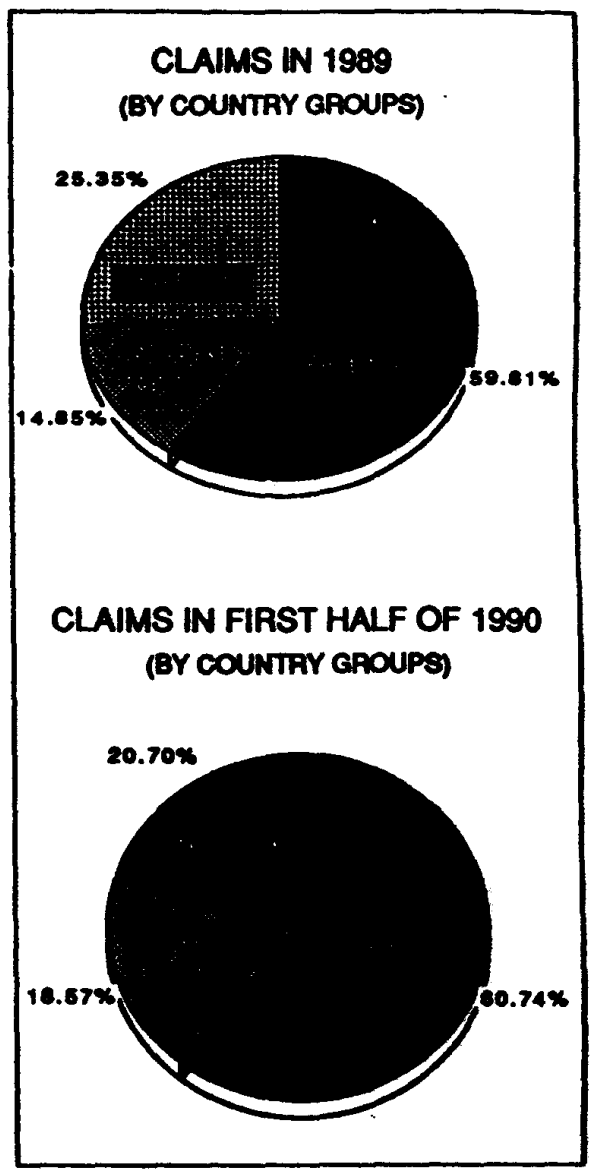

Implementation of such a dymamic and self-responsive mechanism to the process will have a very significant reduction in the cost of administering the determination process whilst keeping the integrity of the system intact. It would free up a sizable amount of Board's resources to expedite the processing of other claims. More importantly, it is likely to ensure that there will never be a backlog (or 'frontiog') in the system $\square$

Arul S. Aruliah is a consultant on multiculturd, imonigration and nefuger isoses. 